\title{
Detection of nitrogen deficiency in wheat from spectral reflectance indices and basic crop eco-physiological concepts
}

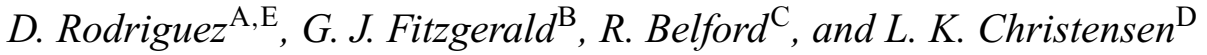

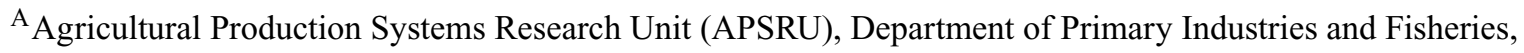 \\ PO Box 102, Toowoomba, Qld 4350, Australia. \\ ${ }^{B}$ USDA-ARS, U.S. Water Conservation Laboratory, 4331 E. Broadway Rd, Phoenix, AZ 85040, USA. \\ ${ }^{\mathrm{C}}$ Primary Industries Research Victoria, PO Box 260, Horsham, Vic. 3401, Australia. \\ DNordic Gene Bank, PO Box 41, SE-23053 Alnarp, Sweden. \\ ${ }^{\mathrm{E}}$ Corresponding author. Email: daniel.rodriguez@dpi.qld.gov.au
}

\begin{abstract}
We tested the capacity of several published multispectral indices to estimate the nitrogen nutrition of wheat canopies grown under different levels of water supply and plant density and derived a simple canopy reflectance index that is greatly independent of those factors. Planar domain geometry was used to account for mixed signals from the canopy and soil when the ground cover was low. A nitrogen stress index was developed, which adjusts shoot $\% \mathrm{~N}$ for plant biomass and area, thereby accounting for environmental conditions that affect growth, such as crop water status. The canopy chlorophyll content index $(\mathrm{CCCi})$ and the modified spectral ratio planar index $\left(\mathrm{mSR}_{\mathrm{Pi}}\right)$ could explain 68 and $69 \%$ of the observed variability in the nitrogen nutrition of the crop as early as Zadoks 33, irrespective of water status or ground cover. The CCCi was derived from the combination of 3 wavebands 670, 720 and $790 \mathrm{~nm}$, and the $\mathrm{mSR}_{\mathrm{Pi}}$ from 445, 705 and $750 \mathrm{~nm}$, together with broader bands in the NIR and RED. The potential for their spatial application over large fields/paddocks is discussed.
\end{abstract}

Additional keywords: water stress, plant density, remote sensing, nitrogen stress index.

\section{Introduction}

The successful adoption of in-season site-specific application of nitrogen $(\mathrm{N})$ fertilisers depends on our capacity to identify areas in a field having differential responses to N. Rapid, reliable, and relatively inexpensive estimates of crop $\mathrm{N}$ status can be made from the analysis of stem juices (Follett et al. 1992) or from estimates of leaf chlorophyll content (Wood et al. 1993). However, these are point estimates that are of limited use when large paddocks need to be analysed.

Remotely sensed spectral indices derived from the reflectance of whole canopies in the green and near infrared have been successfully applied to reduce in-crop $\mathrm{N}$ inputs without reducing grain yield in irrigated maize (Bausch and Diker 2001). When sunlight reaches the crop, most of the irradiance is consumed by water transpiration and a small fraction is used in $\mathrm{CO}_{2}$ assimilation. Part of the light energy is transmitted through the canopy, and part is reflected back towards the observer. Reflected light in the visible region of the electromagnetic spectrum is influenced by the presence of chlorophyll pigments in the leaf tissues, which have been found to relate to the concentration of leaf nitrogen (Thomas and Gausman 1977; Wessman 1990). There are 2 main absorption bands, one in the blue $(450 \mathrm{~nm})$ and another in the red $(670 \mathrm{~nm})$, which are due to the absorption of the 2 main leaf pigments, chlorophyll $a$ and $b$. These account for about $65 \%$ of the total concentration of pigments in higher plants. Approximately $75 \%$ of the plant's total nitrogen is contained in the chloroplasts, mostly in Rubisco and chlorophyll binding proteins (Lawlor 1993). Therefore, remote sensing of chlorophyll content offers the possibility of rapidly estimating crop N status (Blackmer et al. 1986). However, as small amounts of chlorophyll are sufficient to saturate absorption in the $660-680 \mathrm{~nm}$ region, reducing the sensitivity of spectral indices, empirical models to predict chlorophyll content are usually based on reflectance far from pigment absorption maxima, e.g. in the 550 or $700 \mathrm{~nm}$ regions. On the other hand, to obtain maximal sensitivity of the pigment estimation, wavelengths have to be chosen as close as possible to the absorption bands. Another spectral area of considerable interest has been the region between the strong red light absorption by chlorophyll $(680 \mathrm{~nm})$ and the highly reflective near-infrared wavelengths $(780 \mathrm{~nm})$ (Barnes et al. 2000). This region of the spectrum has been referred to as the 'red edge', and several red edge indices have been described (Vogelmann et al. 1993; Filella and Peñuelas 1994; Barnes et al. 2000). In nitrogen deficient 
crops, chlorophyll reduction causes light reflectance in the visible range (400-700 nm) to increase (Yoder and PettigrewCrosby 1995). Relative spectral indices of the $\mathrm{N}$ nutrition of wheat crops have been developed from comparisons with readings from well-fertilised strips (Raun et al. 2001) or calibration stamps (Raun et al. 2005). This avoids the need for calibrating the relationship between nitrogen content and crop reflectance, different growth stages or cultivars, and the need to convert data to surface reflectance factors (Pinter et al. 2003).

In field crops, the main source of variation is the simultaneous presence of water and $\mathrm{N}$ stress (Osborne et al. 2002). Moran et al. (1989) found that water-stressed canopies of alfalfa had a lower spectral reflectance in both the NIR and red wavebands due to changes in canopy architecture. They also found that the perpendicular vegetation index (PVI; Richardson and Wiegand 1977) decreased with stress-induced changes in the architecture of the crop, whereas the NIR/red ratio remained relatively constant. Bowman (1989) showed that the reflectance from cotton (Gossypium hirsutum L.) canopies in the near infrared and shortwave infrared regions $(810,1665$, and $2210 \mathrm{~nm}$ ) increased as the relative water content of the leaves decreased. Thus, the spectral signatures from nutrient deficiencies change when water deficiency is present and this change reduces, if not removes, the symptom-specific spectral characteristics. In addition, the spectral signature of waterstressed crops can be further confounded by the increasing proportions of bare soil and the reduced signals from smaller canopies.

In this work, we $(a)$ tested whether changes in canopy structure and canopy properties, as induced by contrasting crop densities and water regimes, would affect our capacity to predict the nitrogen status of wheat canopies from ground-based multispectral canopy reflectance indices; and (b) developed a simple methodology to identify nitrogenstressed wheat canopies of crops growing under contrasting plant densities and levels of water supply.

\section{Material and methods}

\section{Crops, treatments, and experimental design}

A field experiment was conducted at Horsham, Vic, Australia $\left(36.65^{\circ} \mathrm{S}\right.$, $142.10^{\circ} \mathrm{W}$ ) on a Horsham clay, a Grey Vertisol (Isbell 1966). At sowing, soil mineral nitrogen content was $180 \mathrm{~kg} \mathrm{~N} / \mathrm{ha}(0-1 \mathrm{~m})$, soil phosphorus content $30 \mathrm{mg} / \mathrm{kg}(0-0.2 \mathrm{~m})$ (Colwell 1963), and soil $\mathrm{pH}_{\mathrm{H}_{2} \mathrm{O}}$ was $8.8(0-1 \mathrm{~m})$. Wheat (Triticum aestivum L. cv. Chara) was sown on 17 June 2004. At sowing a triple super phosphate fertiliser $\left(46 \% \mathrm{P}_{2} \mathrm{O}_{5}\right)$ was applied to the entire experimental site at a rate of $61 \mathrm{~kg}$ fertiliser $/ \mathrm{ha}$. The crop emerged 9 days after sowing. Two seeding rates (52 and $102 \mathrm{~kg} \mathrm{seed} / \mathrm{ha}), 4 \mathrm{rates}$ of nitrogen fertiliser $(0,16,39$, and $163 \mathrm{~kg} \mathrm{~N} / \mathrm{ha})$ applied as urea $(46 \% \mathrm{~N})$, and 2 water regimes (irrigated and rainfed), were combined in a factorial experiment with 3 replicates. Treatments were arranged in a split-plot design where nitrogen and density levels were randomised to subplots within the irrigation main plots. The irrigated plots were watered using an automatic sprinkler system every time the accumulated rainfall deficit reached $20-50 \mathrm{~mm}$ from the decile 9 of historical in-crop rainfall in Horsham (SILO station \#79023,
Polkemmet). Rainfall was $270 \mathrm{~mm}$ for the rainfed treatment, and rainfall plus irrigation was $390 \mathrm{~mm}$ for the irrigated treatment, corresponding to deciles 5.3 and 9.3 at Horsham, respectively. There were 6 irrigation events at 76, 93, 100, 113, 121 and 149 days after emergence (DAE). Weeds, pests, and diseases were frequently monitored and controlled as required. Further experimental details can be found in Rodriguez et al. (2005).

\section{Remote sensing of canopy properties and crop measurements}

Samplings took place at 51, 66, 90, 106, and 118 DAE, coinciding with 4 leaves unfolded (Zadoks 14), early tillering (Zadoks 30), mid tillering (Zadoks 33), booting (Zadoks 47), and anthesis (Zadoks 60), respectively. At each sampling date, canopy reflectance measurements were made using a portable spectroradiometer (FieldSpec Pro JR ASD, Co, USA) with a $25^{\circ}$ field of view. The spectroradiometer has a range of $350-2500 \mathrm{~nm}$ with spectral resolution varying between 3.0 and $10 \mathrm{~nm}$, depending on wavelength (ASD 2002). Readings were taken under clearsky conditions in reflectance mode, after standardisation with a level 99\% Spectralon panel (Spectralon, Labsphere Inc., North Sutton, NH). Data were collected at $40-50^{\circ}$ solar zenith angle in a nadir orientation. The spectroradiometer was mounted on a 4-wheel drive motorbike, and the sensor optic head was fitted at the end of a 2-m-long boom and held at $3 \mathrm{~m}$ above the soil surface, yielding a spot size of $1.39 \mathrm{~m}^{2}$. Two recordings, consisting of averages of 25 scans, were taken from each plot at each sampling. Immediately after completing the readings of canopy reflectance, samples of shoots were collected for measurement of leaf area, whole shoot dry weight (stem, sheath + laminae, and ears), and shoot nitrogen percent (shoot N\%). Leaf areas were recorded using a leaf area meter (LI-Cor 3000, LI-Cor Inc., NE, USA) and total nitrogen was determined using a LECO CN2000 (LECO Cor., MI, USA). The sampled area consisted of 3 consecutive rows, 0.5 -m-long spaced at $0.27 \mathrm{~m}$, yielding $\approx 0.4 \mathrm{~m}^{2}$ within the field of view of the spectroradiometer.

\section{Data analysis}

Several reflectance bands and published spectral reflectance indices (Table 1) were derived from the hyperspectral measurements of canopy reflectance taken with the FieldSpec spectroradiometer. Using shoot $\mathrm{N} \%$ as the dependent variable in a partial least squares (PLS) regression modelling, important reflectance indices were identified from their loading weights (Wold et al. 1984). Loading weights are specific to PLS and express how the information in each independent variable relates to the variation in the dependent variable. Independent variables with large loading weight values are important for the prediction of the dependent variable. Calculations were carried out using Unscrambler v.7.5 (CAMO, ASA, Norway), a chemometric software package for multivariate data analysis.

When analysing mixed spectral signals from heterogeneous canopies composed of soil and vegetation elements within the field of view of the sensor, a methodology is required to derive meaningful indices representing the quality of the desired target, e.g. shoot $\mathrm{N} \%$ in the vegetation. Planar domain indices were used to improve the prediction of shoot $\mathrm{N} \%$ by minimising the interference from a changing proportion of bare soil (Clarke et al. 2001). Planar domain indices are created by measuring the proportion of the target component, i.e. vegetation, as its percentage in the whole, i.e. vegetation plus soil elements in the field of view of the instrument, and uses this variable to evaluate the quality of the signal. Hence, 2 indices are needed, one to measure the proportion of the element in the whole, and the other to define some intrinsic property of the element which is of interest (Clarke et al. 2001). In this work we used the normalised difference vegetation index (NDVI) to represent the proportion of crop in the field of view of the spectrometer, and 2 other spectral indices as indicators of the nitrogen status of the crop element. 
Table 1. List of acronyms, bands and reflectance indices, estimated biological parameters, and references analysed in this work

\begin{tabular}{llll}
\hline Index & Formulation & $\begin{array}{c}\text { Estimated biological } \\
\text { parameter }\end{array}$ & Reference \\
\hline NDVI & NIR - Red & Green biomass & Gamon et al. (1995) \\
GNDVI & $\frac{\mathrm{R}_{780}-\mathrm{R}_{550}}{\mathrm{R}_{780}+\mathrm{R}_{550}}$ & Green biomass & Gitelson and Merzlyak (1994) \\
SAVI & $1.5 \cdot \frac{\mathrm{R}_{800}-\mathrm{R}_{670}}{\mathrm{R}_{800}+\mathrm{R}_{670}+0.5}$ & Green biomass & Huete (1988) \\
WI & $\frac{\mathrm{R}_{900}}{\mathrm{R}_{970}}$ & Water content & Peñuelas et al. (1993) \\
Ch1 I & $\frac{\mathrm{R}_{740}}{\mathrm{R}_{720}}$ & Chlorophyll & Vogelmann et al. (1993) \\
NDI1 & $\frac{\mathrm{R}_{750}-\mathrm{R}_{705}}{\mathrm{R}_{750}+\mathrm{R}_{705}}$ & Chlorophyll & Gitelson and Merzlyak (1994) \\
NDI2 & $\frac{\mathrm{R}_{780}-\mathrm{R}_{710}}{\mathrm{R}_{780}-\mathrm{R}_{680}}$ & Chlorophyll & Datt (1999) \\
NDI3 & $\frac{\mathrm{R}_{850}-\mathrm{R}_{710}}{\mathrm{R}_{850}-\mathrm{R}_{680}}$ & Chlorophyll & Datt (1999) \\
mND & $\frac{\mathrm{R}_{750}-\mathrm{R}_{705}}{\mathrm{R}_{750}+\mathrm{R}_{705}-2 \mathrm{R}_{445}}$ & Chlorophyll & Sims and Gamon (2002) \\
mSR & $\frac{\mathrm{R}_{750}-\mathrm{R}_{445}}{\mathrm{R}_{705}-\mathrm{R}_{445}}$ & Chlorophyll & Sims and Gamon (2002) \\
NDRE & $\frac{\mathrm{R}_{790}-\mathrm{R}_{720}}{\mathrm{R}_{790}+\mathrm{R}_{720}}$ & Nitrogen status & Barnes et al. (2000) \\
\hline
\end{tabular}

NDVI, Normalised difference vegetation index; GNDVI, green normalised difference vegetation index; SAVI, soil adjusted vegetation index; WI, water index; Chl I, chlorophyll index; NDI 1-3, Normalised difference indices; mND, modified normalised index; mSR, modified simple ratio; NDRE, normalised difference red edge.

\section{Results}

\section{Spectral signals}

Figure 1 shows that most of the chlorophyll indices (mSR, Chl1, NDI1, NDI2 and mND) had high and positive loading weights, indicating that they were important and positively related to the observed variation in shoot $\mathrm{N} \%$. The normalised difference red edge (NDRE), normalised difference vegetation index (NDVI), the green NDVI and NDI3 indices had an intermediate value to describe $\mathrm{N} \%$, and the water stress index (WI) had a low positive loading weight.

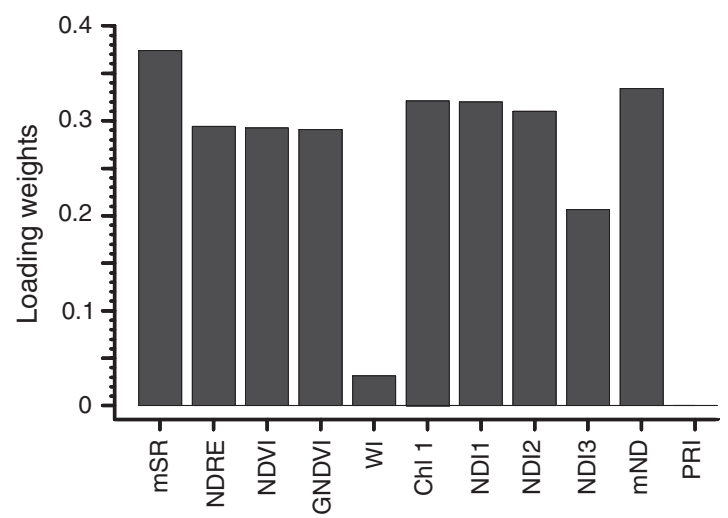

Fig. 1. Loading weights from the partial least square regression analysis between several published multispectral indices and shoot $\mathrm{N} \%$. These indices are defined in Table 1. Samples 1 and 2 were excluded in the analysis.

\section{Plant growth, shoot N\%, and spectral indices}

The maximum values of leaf area index (LAI) were observed for the highest $\mathrm{N}$ levels ( $163 \mathrm{~kg} \mathrm{~N} / \mathrm{ha})$, i.e. 3.1 and $2.6 \mathrm{~m}^{2} / \mathrm{m}^{2}$ for the rainfed low and high densities, and $5.6 \mathrm{~m}^{2} / \mathrm{m}^{2}$ for both the irrigated low and high density treatments, respectively (Fig. 2a-d). High nitrogen supply and high plant densities had higher values of LAI starting early in the season, i.e. sampling $1(P=0.013$ and $P=0.005$, respectively) and at 51 DAE (Zadoks 14). Nitrogen supply significantly increased the values of LAI for samplings 3, 4 and $5(P<0.001)$. Irrigation significantly increased the values of LAI at sampling $4(P<0.02)$ and sampling 5 $(P<0.001)$. The effects of irrigation were more important at the highest levels of $\mathrm{N}$ supply, i.e. 2- and 2.9-fold increases in LAI for samplings 4 and 5, respectively (nitrogen $\times$ irrigation, $P<0.001$ ). Shoot $\mathrm{N} \%$ decreased with the time from emergence (Fig. $2 e-h$ ), and was affected by the treatments as early as sampling 2 (66 DAE, Zadoks 30$)$. Shoot $\mathrm{N} \%$ increased with $\mathrm{N}$ supply $(P<0.001)$ and was higher in the low plant density plots $(P<0.001)$, whereas the effect of plant density was more important at low levels of $\mathrm{N}$ supply $(\mathrm{N} \times$ density $P=0.005)$. Irrigated plots had a higher shoot N\% at sampling $4(P=0.028,106$ DAE, Zadoks 47). No significant interactions were observed with shoot $\mathrm{N} \%$ among the studied factors.

From an ANOVA analysis, high plant density plots had significantly higher values $(P<0.001)$ for the NDRE, and mSR indices at samplings 1 and 2. Early in the season, at sampling 2 , the values of NDI2 $(P<0.01)$, NDI3 $(P<0.01)$, 

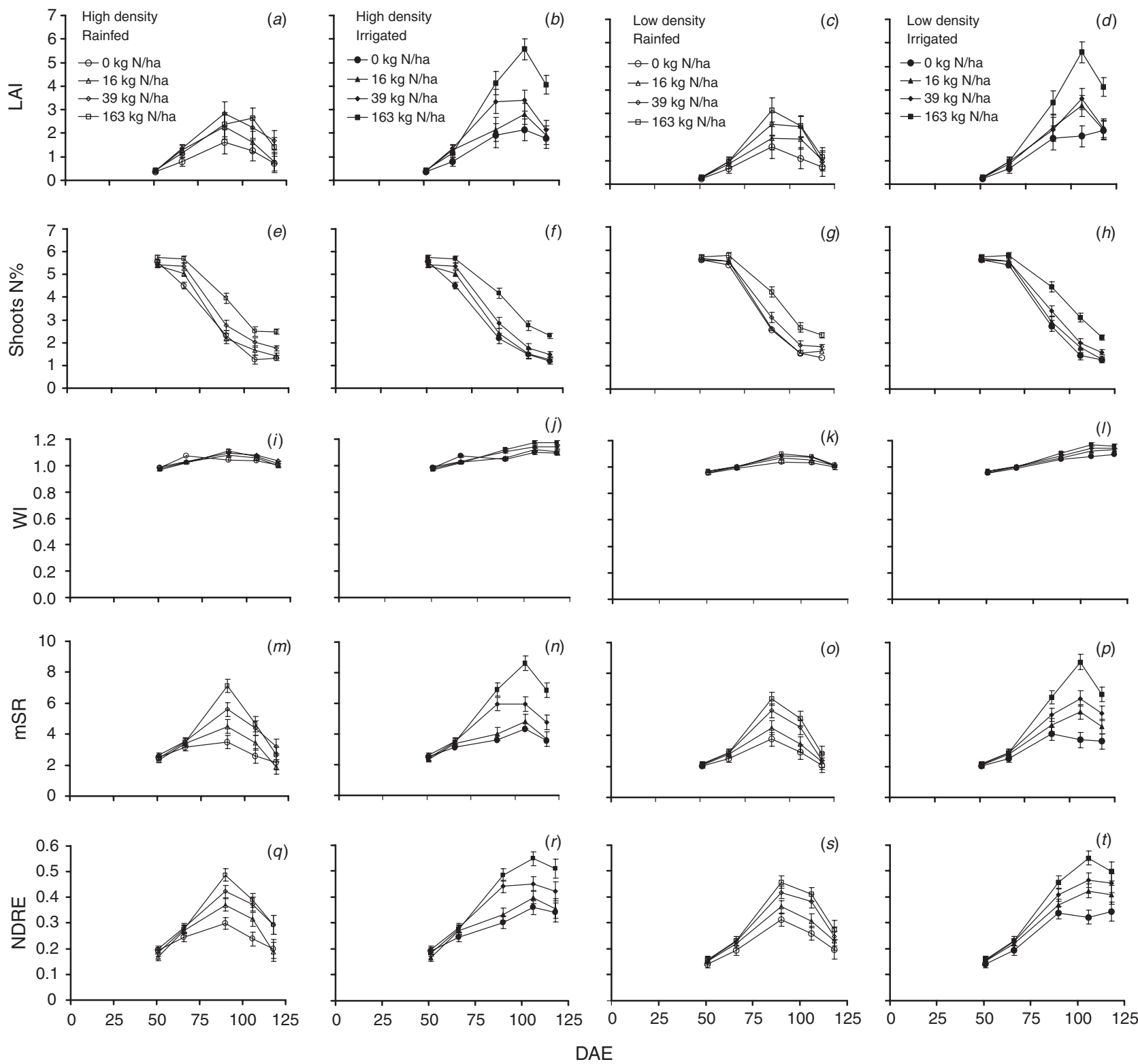

Fig. 2. Time course of leaf area index (LAI), shoot N\%, and the spectral indices [water content (WI), modified spectral ratio (mSR), and normalised difference red edge (NDRE)], for the high $(a, b, e, f, i, j, m, n, q$, and $r$ ) and low plant densities $(c, d, g, h, k, l, o, p, s$, and $t)$, and rainfed (open symbols) and irrigated (closed symbols) wheat crops growing under 4 levels of nitrogen supply $(0,16,39$, and 163 kg N/ha).

and NDRE $(P=0.05)$ increased with the application of $\mathrm{N}$, whereas at samplings 3,4 and 5 all spectral indices were significantly affected by $\mathrm{N}$ treatments $(P<0.001)$. Among all the spectral indices, the water stress index (WI) showed the smallest variation across the studied treatments (Fig. $2 i-l$ ). Water stress reduced the values of all the indices at samplings 4 and $5 \quad(P<0.01)$, although this reduction was particularly important at the highest levels of $\mathrm{N}$ supply $(\mathrm{N} \times$ irrigation, $P<0.01)$, i.e. in those plots where the water stress was most intense. Despite several indices showing potential to discriminate between different levels of shoot N\% (Fig. 2), in this manuscript we only present a more detailed analysis on a chlorophyll index (mSR) and a nitrogen content index (NDRE).

Interactions between the $\mathrm{N}$ and irrigation treatments were also identified when shoot $\mathrm{N} \%$ was plotted as a function of NDRE and mSR (Fig. $3 a, b$ ). No relationship was observed between shoot $\mathrm{N} \%$ and the spectral indices for samplings 1 and 2 (points not shown). Further analysis was therefore limited to samplings 3 (Zadoks 33) to 5 (Zadoks 60). 

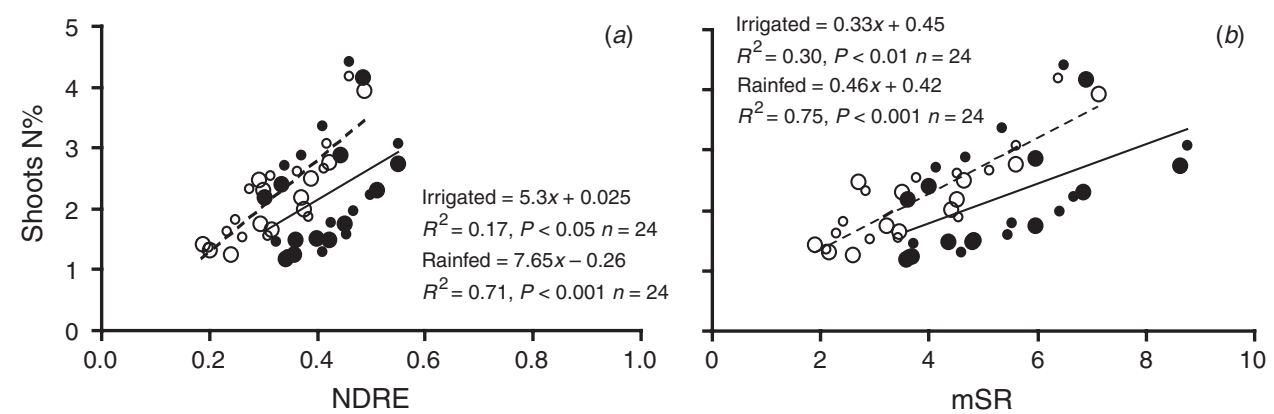

Fig. 3. Relationships between shoot $\mathrm{N} \%$ and ( $a$ ) the normalised difference red edge (NDRE), and $(b)$ the modified spectral ratio (mSR), for the high (large symbols) and low (small symbols) plant densities, rainfed (open circles), and irrigated (closed circles) wheat crops growing under four levels of nitrogen supply $(0,16,39$ and $163 \mathrm{~kg} \mathrm{~N} / \mathrm{ha})$. Samples 1 and 2 were excluded.

\section{Derived indices}

Spectral indices were modified by applying planar domain geometry concepts (Clarke et al. 2001) (Fig. 4). Planar domain indices were empirically derived for the $\mathrm{mSR}$ (Fig. $5 a$ ) and the NDRE (Fig. 5b), converting them into the mSR $_{\mathrm{Pi}}$ and the CCCi (Barnes et al. 2000). The approach requires determining upper and lower limits of $\mathrm{mSR}$ and NDRE as a function of NDVI as shown in Figs 4 and $5 a, b$ by fitting a line that just encompasses the data range. Figure $6 a$ and $b$ shows that normalising the spectral indices by an index of the level of ground cover (NDVI) did not help to account for the observed interactions between the nitrogen and irrigation treatments on the relationship between the $\mathrm{mSR}_{\mathrm{Pi}}$ or $\mathrm{CCCi}$ and shoot $\mathrm{N} \%$.

The rate of $\mathrm{N}$ uptake of any crop is highly variable according to crop development, seasons, plant stands, and sites. However, under ample soil $\mathrm{N}$ availability, crop $\mathrm{N}$ accumulation is highly related to crop growth rate and to biomass accumulation (Greenwood et al. 1986), which may allow for comparisons among irrigation levels and plant densities as in our experiment. In Fig. 7, we show the derivation of a nitrogen stress index $\left(\mathrm{NS}_{\text {index }}\right)$

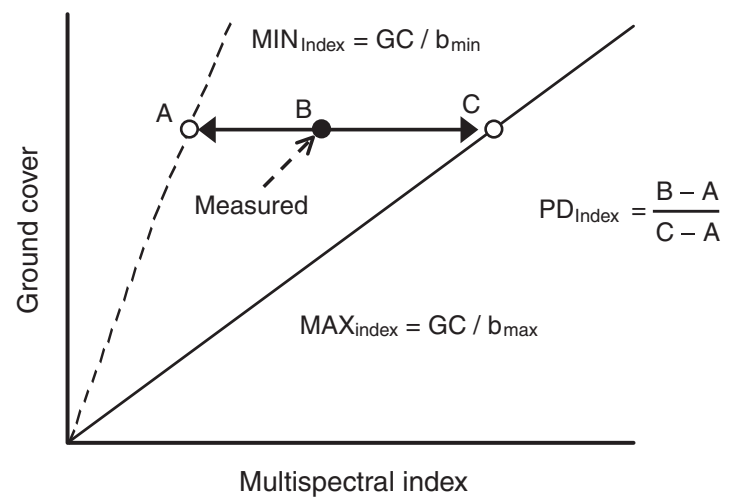

Fig. 4. General shape of a planar domain index $\left(\mathrm{PD}_{\text {Index }}\right)$ for soil/canopy mixed spectral information as in Clarke et al. (2001). from the relationship between shoot $\mathrm{N} \%$ and shoot dry weight.

The nitrogen stress index derived from scaling the crop property target, i.e. shoot $\mathrm{N} \%$ by the accumulation of biomass was poorly described by the multispectral indices NDRE or mSR (Fig. 8a,b); however, the derived planar domain indices $\mathrm{CCCi}$ and $\mathrm{mSR}_{\mathrm{Pi}}$, explained 68 and $69 \%$ of the observed variation in the $\mathrm{NS}_{\text {index }}$, irrespective of level of plant density

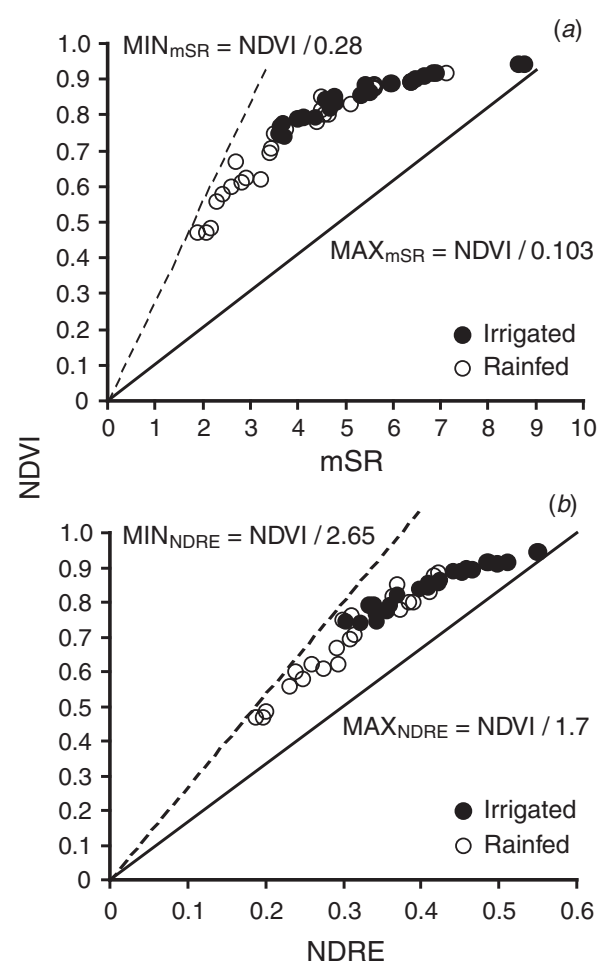

Fig. 5. Derivation of the planar domain indices, from the relationships between a measure of the proportion of the target (ground cover) in the field of view of the sensor (represented by NDVI) and the signal from the target property of interest (shoot $\mathrm{N} \%$ ) represented by the spectral indices $(a)$ the modified spectral ratio (mSR), and $(b)$ the normalised difference red edge (NDRE). Samples 1 and 2 were excluded. 

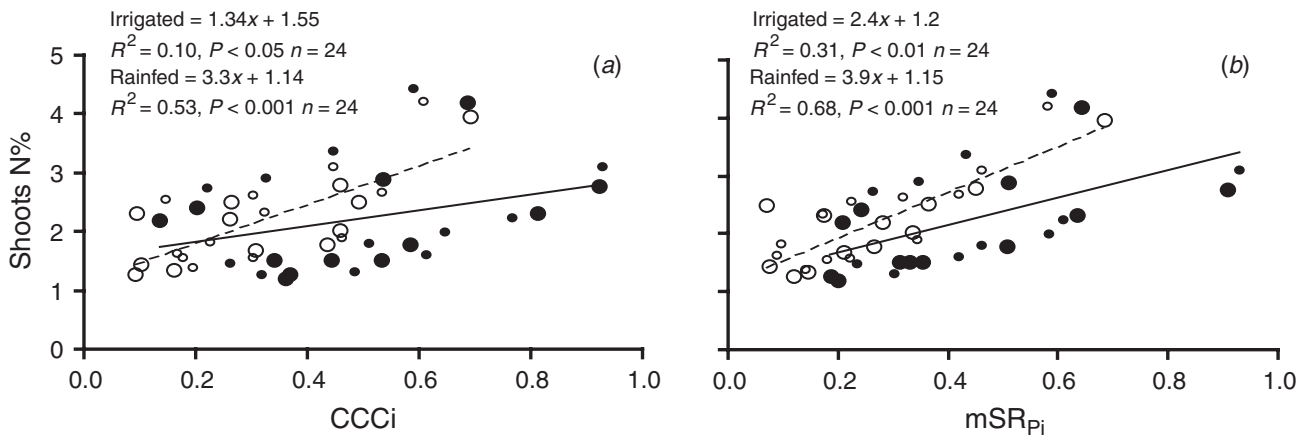

Fig. 6. Relationships between the shoot $\mathrm{N} \%$ and $(a)$ the planar domain indices derived from the normalised difference red edge, i.e. canopy chlorophyll content index (CCCi), and $(b)$ the modified spectral ratio $\left(\mathrm{mSR}_{\mathrm{Pi}}\right)$. The small and large symbols indicate low and high canopy densities, respectively, and the open and closed symbols show the rainfed and irrigated treatments, respectively. Samples 1 and 2 were excluded.

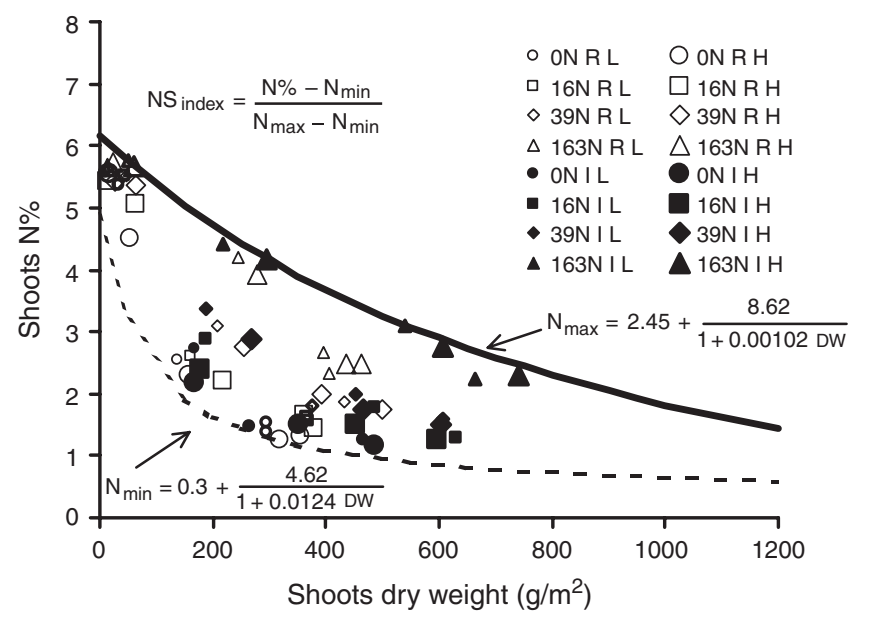

Fig. 7. Derivation of the nitrogen stress index $\left(\mathrm{NS}_{\text {index }}\right)$ from the relationship between shoot $\mathrm{N} \%$ and shoot dry weights. The legend in the graph identifies the nitrogen levels $(0,16,39$ and $163 \mathrm{~kg} \mathrm{~N} / \mathrm{ha})$, irrigation treatments ( $\mathrm{R}$, rainfed; $\mathrm{I}$, irrigated), and canopy density (L, low; $\mathrm{H}$, high). $\mathrm{N}_{\max }$ and $\mathrm{N}_{\min }$ are the manually fitted upper and lower bounds of the relationship between shoot N\% and shoot dry weight.

or irrigation (Fig. $8 c, d$ ). The slope and intercept of the regression lines in Fig. $8 c, d$ did not differ from those of the separate irrigated and rainfed treatments (slopes and intercept in Fig. $8 c, P<0.712$ and $P<0.078 n=48$; and in Fig. $8 d$, $P<0.66$ and $P<0.11 n=48$, respectively).

\section{Discussion}

Although the data are only from a single growing season, the treatments applied created a wide range of canopy densities, structure, water status, and nitrogen level, commensurate with most typical growing conditions in south-eastern Australia. Maximum leaf area index ranged from 2.4 to $5.6 \mathrm{~m}^{2} / \mathrm{m}^{2}$ at Zadoks 47. Shoot N\% ranged from 5.4 to $5.7 \%$ at Zadoks 1.4, from 5 to $5.7 \%$ at Zadoks 30 , from 2.8 to $4.4 \%$ at Zadoks 33 , from 1.25 to $3.1 \%$ at Zadoks 47 , and from 1.2 to $2.5 \%$ at Zadoks 60 . In a previous paper on this experiment,
Rodriguez et al. (2005) also showed that the grain yields ranged from 525 to $4862 \mathrm{~kg} / \mathrm{ha}$, and that a canopy water stress index (CSI) determined at anthesis varied from 1.1 to $4.6^{\circ} \mathrm{C} / \mathrm{kPa}$ among the treatments.

The main source of nitrogen for crops in soils of southeastern Australia is from the breakdown of organic N accumulated under the original vegetation (Angus et al. 1998) and from $\mathrm{N}$ fixation during the legume phase of the rotation (McCallum et al. 2000). Simulated wheat yields under optimal management for the Wimmera region (O'Leary and Connor 1998) showed a maximum of $5.4 \mathrm{t} / \mathrm{ha}$, with a longterm median of $4 \mathrm{t} / \mathrm{ha}$, although yields of $8 \mathrm{t} / \mathrm{ha}$ are not uncommon under irrigation at the Plant Breeding Centre in Horsham, where this experiment took place (D. Pye, pers. comm.). Based on those yields, total $\mathrm{N}$ demand would then range from 121 to $242 \mathrm{~kg} \mathrm{~N} / \mathrm{ha}$, of which $67-195 \mathrm{~kg} \mathrm{~N} / \mathrm{ha}$ can be present in the soil at sowing, and 43 to $99 \mathrm{~kg} \mathrm{~N} / \mathrm{ha}$ could be mineralised during the cropping season (Angus et al. 1998). This indicates that under rainfed conditions, the margin for improving the nitrogen nutrition of the crop is small and that the most likely benefit of identifying zones in the field having a differential response to $\mathrm{N}$ would be the avoidance of losses in the non-responsive areas (Cook and Bramley 1998). Application of remote sensing techniques to identify zones of differential potential response to $\mathrm{N}$ at the paddock scale have been rare in Australia. One reason for this is the lack of affordable and simple methods capable of spatially identifying $\mathrm{N}$ status across large areas in the field that are independent of environmental and site conditions, i.e. ground cover and the simultaneous occurrence of water stress.

\section{Remote sensing of nitrogen deficiency}

In this paper, we used several published indices (Table 1) to evaluate their capacity to predict nitrogen concentration in shoots of wheat canopies growing under contrasting levels of nitrogen, density, and water supply. Simple ratios typically divide the reflectance at a reference wavelength 

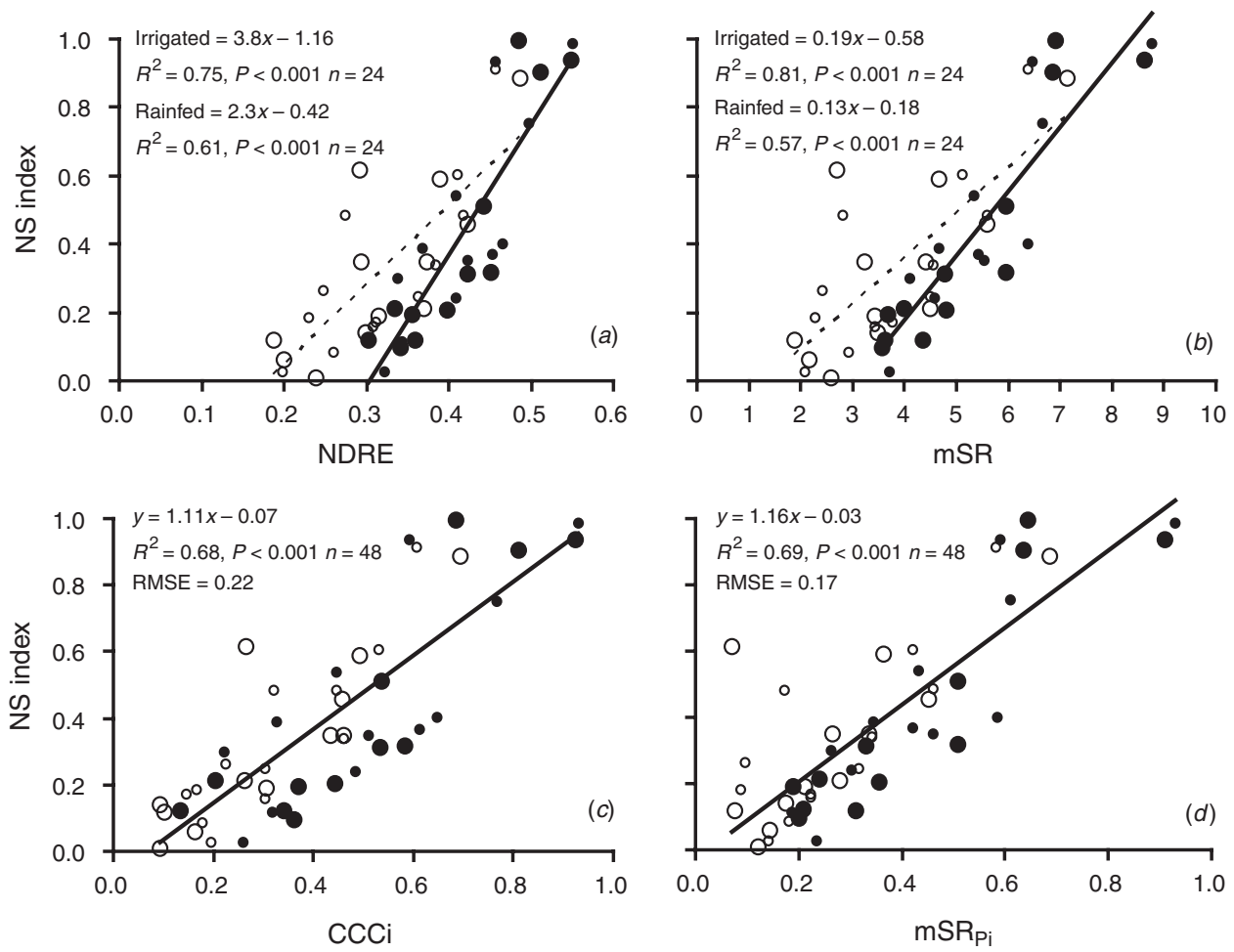

Fig. 8. Relationships between the nitrogen stress index $\left(\mathrm{NS}_{\text {index }}\right)$ and $(a)$ the normalised difference red edge (NDRE), $(b)$ the modified spectral ratio $(\mathrm{mSR}),(c)$ planar domain canopy chlorophyll content index $(\mathrm{CCCi})$, and $(d)$ modified spectral ratio $\left(\mathrm{mSR}_{\mathrm{Pi}}\right)$. Open and closed symbols indicate the rainfed and irrigated treatments, and small and large symbols show the low and high canopy densities, respectively. The root mean squared errors (RMSE) are included in Fig. $8 c$ and $d$. Samples 1 and 2 were excluded.

(typically between 750 and $900 \mathrm{~nm}$ ) by an index wavelength (typically between 660 and $720 \mathrm{~nm}$ ) (Sims and Gamon 2002). Reference wavelengths are independent of the stage of leaf development due to negligible chlorophyll absorption. Reflectance at these wavelengths is mostly driven by the light scattering properties of the leaves. Reflectance at 555 and $705 \mathrm{~nm}$ was found to be maximally sensitive to variations in chlorophyll and these wavelengths have been used as index wavelengths (Gitelson and Merzlyak 1994). To compensate for high leaf surface (specular) reflectance, which tends to increase reflectance across the whole visible spectrum, Sims and Gamon (2002) used the reflectance at $445 \mathrm{~nm}$ to define a modified simple ratio (mSR). Pigment absorption is minimal at this wavelength. Indices based on NDVI use similar wavelengths to the simple ratios but subtract rather than divide, the index from the reference, and the value is normalised through division by the sum of the reflectance at the same 2 wavelengths (Sims and Gamon 2002). In our work we used the NDRE, which uses a reference band in the edge band region $(720 \mathrm{~nm})$ in combination with a vegetation index.

The loading weights derived from a PLS1 regression analysis (Fig. 1), indicated that several indices were highly related to the variation observed in shoot N\%. Since temporal changes in LAI and shoot $\mathrm{N} \%$ across the treatments were better related to the observed temporal variations in the mSR and NDRE indices (Fig. 2), we limited our analysis to these two. The NDRE index has been successfully used in cotton to identify nitrogen stress from other causes of reduced green biomass (Barnes et al. 2000; Clarke et al. 2001). The NDI3 and WI indices showed little sensitivity to the effects of the nitrogen treatments on shoot $\mathrm{N} \%$, and none of the indices was capable of explaining the nitrogen status of the crop early in the season at Zadoks 14 and 30 (Fig. 2). Our results showed that water supply and plant density were important confounding factors when trying to derive empirical predictive relationships between the spectral indices and shoot N\%. In Fig. $3 a, b$, no single relationship could account for all the treatments. The capacity of the spectral indices to discriminate different levels of nitrogen was smaller in the water-stressed plots, and was particularly reduced when the intensity of the water stress was maximised in the high-N, high plant density plots, and for the anthesis sampling (Fig. 2). Confounding effects can originate from changes in canopy architecture, i.e. leaf rolling and leaf angle (Moran et al. 1989), reflectance coming from the bare soil (Bausch 1993; Clarke et al. 2001), and probably from changes in properties of leaf surfaces (Chaves et al. 2003). It has been suggested that measuring the proportion of the 
targetted component (i.e. crop) in the field of view of the sensor can be used to evaluate the quality of the signal and reduce unwanted spectral signals when the ground cover is incomplete (Clarke et al. 2001). We used planar domain geometry as in Clarke et al. (2001) to derive the CCCi (Barnes et al. 2000), and a new additional index $\mathrm{mSR}_{\mathrm{Pi}}$ (Figs 4 and 5). The relationship between shoot N\% and the planar domain indices, $\mathrm{CCCi}$ and $\mathrm{mSR}_{\mathrm{Pi}}$, was still affected by the water status of the crop (Fig. $6 a, b$ ). Variability in the accumulation of crop $\mathrm{N}$ across environments has been observed to be reduced when crop $\mathrm{N}$ content is related to crop biomass (Gastal and Lemaire 2002). The relationship between shoot N\% and shoot biomass accumulation in crops (Fig. 7) relies on the inter-regulation of multiple crop physiological processes; among them, $\mathrm{N}$ uptake, crop $\mathrm{C}$ assimilation (and thus growth rate), and $\mathrm{C}$ and $\mathrm{N}$ allocation between organs, all processes influenced by the water status of the crop. In our experiment, water-stressed plants had lower biomass but similar shoot $\mathrm{N} \%$ when compared with the well-irrigated treatments. This obviously modifies the amount of nitrogen detected in the crop when it is calculated or sensed per unit area. To overcome this problem, we devised a per area base nitrogen stress index $\left(\mathrm{NS}_{\text {index }}\right)$ that normalises shoot $\mathrm{N} \%$ as a function of shoot biomass (Fig. 7). Despite important variations in the level of water stress and canopy density among treatments and sampling times, the planar domain indices, $\mathrm{CCCi}$ and $\mathrm{mSR}_{\mathrm{Pi}}$, were capable of explaining 68 and $69 \%$ of the observed variability of $\mathrm{NS}_{\text {index }}$ as early as Zadoks 33 (Fig. 8c, $d$ ).

Direct application of the results obtained in this paper can be achieved by customising airborne image acquisition systems, e.g. a 3-CCD digital camera, using the identified wave bands. The relationships developed in Fig. $8 c$ and $d$ can be used for variable rate applications of top-dressed fertilisers in wheat crops as early as Zadoks 33. In south-eastern Australia this corresponds to the months of July-August, a time of the year when farmers consider top-dressing wheat crops, and a time of year when the existing seasonal climate forecasting tools, such as the 5 SOI phase system (Stone and Auliciems 1992), start showing levels of forecasting skill higher than $70 \%$ consistent (Anwar et al. 2004) and economic value for in-season crop nitrogen management (Lythgoe et al. 2004).

\section{Conclusions}

With this paper we addressed the problem that even though remote sensing of the nitrogen status of the crop has been around for a long time, so far not many applications of the technology are available to the Australian farmers. We showed that the existence of confounding factors such as the level of ground cover and water status of the crop, and a lack of a physiological understanding regarding what is relevant as a prediction, can limit the value of the technology. To assist farmers with in-crop $\mathrm{N}$ management, we propose that we should not aim to predict N\%, but indices indicative of potential for response to additional $\mathrm{N}$ additions. We also demonstrated how simple reflectance indices are affected by confounding factors, and how a simple methodology could be devised to make the derived indices more meaningful and relevant to the decision maker.

We tested several published multispectral indices for their capacity to estimate the nitrogen nutrition of wheat canopies grown under different levels of water supply and plant density and derived a new simple canopy reflectance index $\left(\mathrm{mSR}_{\mathrm{Pi}}\right)$. This new index was derived from the combination of 3 narrow bands $(445,705$, and $750 \mathrm{~nm})$ together with broader bands in the NIR and RED (NDVI). The CCCi from Barnes et al. (2000), and the $\mathrm{mSR}_{\mathrm{Pi}}$ indices can be used as spatial indicators of the nitrogen status of wheat canopies with great independence of the water status of the crop and plant density. The results in this paper highlight the importance of taking into consideration basic eco-physiological understanding when analysing remotely sensed spectral data from fieldgrown wheat canopies.

\section{Acknowledgments}

This work was fully funded by the Department of Primary Industries of Victoria, Australia. We greatly appreciate the excellent field work done by Russel Argall. We appreciate the comments made by Dr Graeme Wright and Tom Clarke on early versions of this manuscript. We also thank the personnel at the USA Water Conservation Laboratory for their hard work and dedication.

\section{References}

Angus JF, van Herwaarden AF, Fischer RA, Howe GN, Heenan DP (1998) The source of mineral nitrogen for cereals in south-eastern Australia. Australian Journal of Agricultural Research 49, 511-522. doi: 10.1071/A97125

Anwar M, Rodriguez D, Liu DL (2004) Signals from ENSO on climate and grain yield in South Eastern Australia. In '16th New Zealand and Australian Climate Forum'. 8-10 November, Lorne, Victoria, Australia. (Unpaginated CD-ROM)

ASD (2002) 'FieldSpec Pro, User's guide. ASD Part\# 600000. Rev. C.' (Analytical Spectral Devices Inc.: Boulder, CO)

Barnes EM, Clarke TR, Richards SE, Colaizzi PD, Haberland J, Kostrzewski M, Waller P, Choi C, Riley E, Thompson T, Lascano RJ, Li H, Moran MS (2000) Coincident detection of crop water stress, nitrogen status and canopy density using ground-based multispectral data. In 'Proceedings of the 5th International Conference on Precision Agriculture'. (Eds PC Robert, RH Rust, WE Larson) (American Society of Agronomy: Madison, WI)

Bausch WC (1993) Soil background effects on reflectance-based crop coefficients for corn. Remote Sensing of Environment 46, 213-222. doi: 10.1016/0034-4257(93)90096-G

Bausch WC, Diker K (2001) Innovative remote sensing techniques to increase nitrogen use efficiency of corn. Communications in Soil Science and Plant Analysis 32, 1371-1390. doi: 10.1081/CSS100104117

Blackmer TM, Schepers JS, Varvel GE (1986) Light reflectance compared with other nitrogen stress measurements in corn leaves. Agronomy Journal 86, 934-938. 
Bowman WD (1989) The relationship between leaf water status, gas exchange and spectral reflectance in cotton leaves. Remote Sensing of Environment 30, 249-255. doi: 10.1016/0034-4257(89)90066-7

Chaves MM, Maroco JP, Pereira JS (2003) Understanding plant responses to drought-from genes to the whole plant. Functional Plant Biology 30, 239-264. doi: 10.1071/FP02076

Clarke TR, Moran MS, Barnes EM, Pinter PJ Jr, Qi J (2001) Planar domain indices a method for measuring a quality of a single component in two-component pixels. In 'Proceedings IEEE International Geoscience and Remote Sensing Symposium'. 9-13 July, Sydney, Australia. (Unpaginated CD-ROM)

Colwell JD (1963) The estimation of the phosphorus fertilizer requirements of wheat in southern New South Wales by soil analysis. Australian Journal of Experimental Agriculture and Animal Husbandry 3, 190-197. doi: 10.1071/EA9630190

Cook SE, Bramley RGV (1998) Precision agriculture — opportunities, benefits and pitfalls of site-specific crop management in Australia. Australian Journal of Experimental Agriculture 38, 753-763. doi: 10.1071/EA97156

Datt B (1999) Visible/near infrared reflectance and chlorophyll content in Eucalyptus leaves. International Journal of Remote Sensing 14, 3081-3092.

Filella L, Peñuelas J (1994) The red edge position and shape as indicators of plant chlorophyll content, biomass and hydric status. International Journal of Remote Sensing 15, 1459-1470.

Follett RH, Follett RF, Halvorson AD (1992) Use of a chlorophyll meter to evaluate the nitrogen status of dryland winter wheat. Communications in Soil Science and Plant Analysis 23, 687-697.

Gamon JA, Field CV, Goulden ML, Griffin KL, Hartley AE, Joel G, Peñuelas J, Valentini R (1995) Relationships between NDVI, canopy structure, and photosynthesis in three Californian vegetation types. Ecological Applications 5, 28-41. doi: 10.2307/1942049

Gastal F, Lemaire G (2002) N uptake and distribution in crops: an agronomical and ecophysiological perspective. Journal of Experimental Botany 53, 789-799. doi: 10.1093/jexbot/53.370.789

Gitelson AA, Merzlyak MN (1994) Spectral reflectance changes associated with autumn senescence of Aesculus hippocastanum L. and Acer platanoides L. leaves. Spectral features and relation to chlorophyll estimation. Journal of Plant Physiology 143, 286-292.

Greenwood DJ, Neeteson JJ, Draycott A (1986) Quantitative relationships for the dependence of growth rate of arable crops on their nitrogen content, dry weight and aerial environment. Plant and Soil 91, 281-301. doi: 10.1007/BF02198111

Huete AR (1988) A soil-adjusted vegetation index (SAVI). Remote Sensing of Environment 25, 295-309. doi: 10.1016/00344257(88)90106-X

Isbell RF (1966) 'The Australian Soil Classification.' (CSIRO Publishing: Melbourne)

Lawlor DW (1993) 'Photosynthesis. Molecular, physiological and environmental processes.' (Longman Scientific \& Technical: Essex, UK)

Lythgoe B, Rodriguez D, Liu DL, Brennan J, Scott B, Murray G, Hayman P (2004) Seasonal climate forecasting has economic value for farmers in south eastern Australia. In 'Proceedings of the 4th International Crop Science Conference'. 26 Sept.-1 Oct. Brisbane, Australia. (Unpaginated CD-ROM)

McCallum MH, Peoples MB, Connor DJ (2000) Contributions of nitrogen by field pea (Pisum sativum L.) in a continuous cropping sequence compared with a lucerne (Medicago sativa L.)based pasture ley in the Victorian Mallee. Australian Journal of Agricultural Research 51, 13-22. doi: 10.1071/AR99023

Moran MS, Pinter PJ, Clothier BE, Allen SG (1989) Effect of water stress on the canopy architecture and spectral indices of irrigated alfalfa. Remote Sensing of Environment 29, 251-261. doi: 10.1016/00344257(89)90004-7
O'Leary GJ, Connor DJ (1998) A simulation study of wheat crop response to water supply, nitrogen nutrition, stubble retention, and tillage. Australian Journal of Agricultural Research 49, 11-19. doi: 10.1071/A97020

Osborne SL, Schepers JS, Francis DD, Schlemmer MR (2002) Detection of phosphorus and nitrogen deficiencies in corn using spectral radiance measurements. Agronomy Journal 94, 1215-1221.

Peñuelas J, Filella I, Biel C, Serrano L, Save R (1993) The reflectance at the $950-970 \mathrm{~nm}$ region as an indicator of plant water status. International Journal of Remote Sensing 14, 1887-1905.

Pinter PJ Jr, Hatfield JL, Schepers JS, Barnes EM, Moran MS, Daughtry CST, Upchurch DR (2003) Remote sensing for crop management. Photogrammetric Engineering and Remote Sensing 69, 647-664.

Raun WR, Solie JB, Johnson GV, Stone ML, Lukina WE, Thomason WE, Schepers JS (2001) In-season prediction of potential grain yield in winter wheat using canopy reflectance. Agronomy Journal 93, 131-138.

Raun WR, Solie JB, Stone ML, Zavodny DL, Martin KL, Freeman KW (2005) Automated calibration stamp technology for improved in-season nitrogen fertilisation. Agronomy Journal 97, 338-342.

Richardson AJ, Wiegand CL (1977) Distinguishing vegetation from soil background information. Photogrammetric Engineering \& Remote Sensing 43, 1541-1552.

Rodriguez D, Sadras VO, Christensen LK, Belford R (2005) Spatial assessment of the physiological status of wheat crops as affected by water and nitrogen supply using infrared thermal imagery. Australian Journal of Agricultural Research 56, 983-993. doi: 10.1071/AR05035

Sims DA, Gamon JA (2002) Relationships between leaf pigment content and spectral reflectance across a wide range of species, leaf structures and developmental stages. Remote Sensing of Environment 81, 337-354. doi: 10.1016/S0034-4257(02)00010-X

Stone RC, Auliciems A (1992) SOI phase relationships with rainfall in eastern Australia. International Journal of Climatology 12, 625-636.

Thomas JR, Gausman HW (1977) Leaf reflectance versus leaf chlorophyll and carotenoid concentrations for eight crops. Agronomy Journal 69, 799-802.

Vogelmann TC, Rock BN, Moss DM (1993) Red edge spectral measurements from sugar maple leaves. International Journal of Remote Sensing 14, 1563-1575.

Wessman CA (1990) Evaluation of canopy biochemistry. In 'Remote sensing of biosphere functioning'. (Eds RJ Hobbs, HA Mooney) pp. 135-156. (Springer-Verlag: New York)

Wold S, Albano C, Dunn WJ, Esbensen K, Hellberg S, Johansson E (1984) Modelling data tables by principal components and PLS: class patterns and quantitative predictive relationships. Analysis 12, 477-485.

Wood CW, Reeves DW, Himelrick DG (1993) Relationships between chlorophyll meter readings and leaf chlorophyll concentration, $\mathrm{N}$ status, and crop yield: A review. Proceedings Agronomy Society of New Zealand 23, 1-9.

Yoder BJ, Pettigrew-Crosby RE (1995) Predicting nitrogen and chlorophyll content and concentrations from reflectance spectra $(400-2500 \mathrm{~nm})$ at leaf and canopy scales. Remote Sensing of Environments 53, 199-211. doi: 10.1016/0034-4257 (95)00135-N

Manuscript received 12 October 2005, accepted 17 February 2006 